\title{
Effect of implementation of safety measures in tae kwon do competition
}

\author{
D T Burke, K Barfoot, S Bryant, J C Schneider, H J Kim, G Levin
}

Br J Sports Med 2003;37:401-404

See end of article for authors' affiliations

Correspondence to: Dr Burke, Department of Physical Medicine and Rehabilitation, Harvard Medical School, Spaulding Rehabilitation Hospital, 125 Nashua Street, Suite \# 753, Boston, MA 02114, USA;

dburke1@partners.org

Accepted 16 September 2002

\begin{abstract}
Background: Previous reviews of tae kwon do (TKD) tournaments have documented injury rates of $25 / 1000$ to $12.7 / 100$ athlete exposures. Most injuries have been reported to be to the head and the neck and are occasionally very serious. Many of these studies involved high level TKD competitions with minimal safety precautions. Recently, safety measures have been implemented in many TKD competitions.

Objective: To evaluate retrospectively the incidence of injuries in TKD competitions involving a wide range of participants and featuring extensive safety precautions.

Methods: A total of 2498 participants ranged in age from 18 to 66, included both men and women, and ranged in rank from yellow to black belt. Traumas, defined as any event requiring interaction with medical staff, were documented with respect to mechanism, diagnosis, treatment, and follow up recommendations. An injury was defined as a trauma that prevented a contestant from resuming competition on the day that the trauma occurred, according to National Collegiate Athletic Association criteria.

Results: The injury rate was $0.4 / 1000$ athlete exposures. This is lower than reported in previous studies of TKD tournaments and in many other sports.

Conclusion: TKD tournaments that emphasise limited contact, protective equipment, and medical supervision are relatively safe and compare favourably with other sports.
\end{abstract}

A estimated 2 million people in the United States participate in the martial arts. ${ }^{1}$ Tae kwon do (TKD) is the most commonly practised of the martial arts. In 1988, it was introduced at the Olympic Games in South Korea. A number of recent studies have evaluated the risk of injury during participation in TKD. ${ }^{1-18}$

The head and neck have been found to be the most common sites of injury. ${ }^{7-11}$ The incidence of these injuries has been considered worrying and competition modifications have been recommended. Oler and colleagues ${ }^{7}$ recommended the use of headgear, mouthguards, groin protection, and floor padding as well as improved medical supervision of tournaments. Zemper and Pieter, ${ }^{10}$ in their review of TKD injury rates in the 1988 US Olympic team trials, also recommended the use of protective headgear. Pieter and Lufting ${ }^{14}$ in their study of the 1991 Tae Kwon Do World Championships, recommended the use of mats to protect against falls to the concrete floor and adoption of suspension rules, such as those used in boxing.

Varying degrees of severity of injury in TKD competition have been described. Birrer ${ }^{12}$ suggested that minor injuries such as contusions, sprains, and strains of the extremities are most common, and that serious injuries rarely occur. In contrast, Siana et $a l^{11}$ found that $4 \%$ of athletes at the 6th Tae Kwon Do World Championship required hospital admission for their injuries. In a study of 4258 children aged 6-16 years, contusions and concussions were the first and second most common injuries respectively. ${ }^{18}$ Oler and colleagues ${ }^{7}$ documented one case of a fatal kick to the head that resulted in an occipital skull fracture, bilateral subdural haematomas, contusion of the frontal and temporal lobes, and haemorrhage and herniation of the brainstem.

The rate of injury in TKD competition has been reported in two different statistical forms: the incidence of injuries per athlete exposures and the percentage of injuries per number of athletes. The reported injury rates range from 25/1000 to $12.7 / 100$ athlete exposures. ${ }^{10}{ }^{15-17}$ The incidence of head and neck injuries range from $8 / 1000$ to $29 / 1000$ athlete exposures..$^{13} 1618$
Given the incidence of injury to the head and neck and the severity of such injuries, safety standards including protective equipment, light contact rules of engagement, and mandatory medical supervision have been proposed by the United States Tae Kwon Do Alliance. ${ }^{19}$ These include many of those proposed by the authors referenced above. ${ }^{1-18}$ "Light contact" entails no contact to the head, face, neck, or groin, only to the headgear. "Light head contact" constitutes any head contact that causes incidental head movement with no injury, abrasion, or flow of blood. The generalisations of previous studies are marred by the fact that their cohorts were homogeneous in terms of experience and skills. For example, some studies concentrated on participants of the Olympics and other major championships. ${ }^{10} 131516$ Such participants are certain to have been black belt in rank and likely to be "elite". Data obtained from these studies therefore probably do not represent the average TKD participant or reflect the true risk of routine participation in the sport. Other studies have been skewed in that they have been limited to a certain age group. ${ }^{8}$ A study is therefore needed of a diverse group of participants in order to examine the incidence of injury in the light of the newly implemented rules of safety. ${ }^{19}$

This study surveyed the injury rate in TKD competition after the implementation of these rules. It is an observational study based on a national and a regional TKD competition which imposed safety regulations essentially complying with the recommendations of the United States Tae Kwon Do Alliance. ${ }^{19}$

\section{METHODS}

This study retrospectively investigated injuries at the United States Tae Kwon Do Alliance national and regional tournaments, both held in New Orleans, Louisiana, in January 1993 and October 1994 respectively. Data were collected by four university based sports medicine physicians, who positioned themselves so that they were able to supervise all of the competitions. 
Table 1 Trauma data for tae kwon do competitions

\begin{tabular}{ll}
\hline Number of athletes & 2498 \\
Reported traumas & \\
Total number of medical interactions & 33 \\
Number of medical staff interventions & 21 \\
Trauma that resulted in restriction of the athlete's participation & 1 \\
Total injury rates & \\
Per 1000 athlete exposures & 0.4 \\
Prevalence & $0.04 \%$ \\
\hline
\end{tabular}

The rules of both tournaments allowed light contact kicks above the belt and anterior to the coronal plane. Kicks to the face were prohibited. All other kicks were counted as "scores." Punches were allowed to all areas between the belt and the base of the neck, and were required to be anterior to the coronal plane to be counted as "scores." Any contact below the belt, to the back, or to the face resulted in a warning and a point for the opponent. Before the tournament, the organisers admonished the judges to enforce the light contact rule strictly.

In accordance with the rules of the United States Tae Kwon Do Alliance national and regional tournaments, ${ }^{19}$ all combatants were required to wear soft foam headgear covering the head and ears, as well as elbow pads, foam gloves covering the hands, and foam coverings of the feet with the plantar surface of the foot exposed. All male competitors were required to wear athletic supports with protective cups.

Medical coverage was provided in three shifts, with a minimum of three doctors, three athletic trainers, and one emergency medical technician present per shift. The referee and the supervising doctor had authority to stop the match if they witnessed an apparent injury. At this point, the tournament doctor examined the competitor. The doctor completed a data form for each examination. All traumas, including the mechanism, diagnosis, location, severity, specific treatment, and any follow up recommendations, were recorded. Note was also made of the participants' age, sex, and belt level. The total number of participants in each tournament was recorded. Traumas were defined as any event that required an athlete to be assessed by medical staff. An injury was defined as any event that required an athlete to cease competition. ${ }^{20}$ In the analysis therefore only those traumas that resulted in interruption of competition for the day were counted as injuries, according to National Collegiate Athletic Association (NCAA) criteria.

Observational data were collected from the two tournaments. The total number of medical interactions, medical interventions, and traumas and injuries as defined above were tabulated. The injury rate per 1000 athlete exposures was calculated as the number of total injuries divided by the total number of athletes at each event. For this calculation, one exposure was equal to one tournament. Data were compared with previously published martial arts injury data as well as published NCAA data on injury in other sports. In addition, the injuries were categorised by cause, location, and diagnosis. As this was a retrospective review of tournament records, informed consent was not obtained. This study was reviewed by the Louisiana State University institutional review board.

\section{RESULTS}

There was a total of 2498 participants in the two tournaments. About 80\% (1998) were drawn from the United States Tae Kwon Do Alliance national tournament and 20\% (500) from the regional tournament. Participants ranged in age from 18 to 66 , included both men and women, and ranged in belt level from yellow to black.

Thirty one tournament participants were examined by the medical staff. Only 21 required medical intervention (most
Table 2 Number of traumas by cause

\begin{tabular}{ll}
\hline Trauma mechanism & Number \\
\hline Participant contact & 20 \\
Fall & 9 \\
Twisting & 1 \\
Unknown & 3 \\
Total & 33 \\
\hline
\end{tabular}

Table 3 Number of traumas by type of trauma*

\begin{tabular}{ll}
\hline Trauma type & Number \\
\hline Contusion & 25 \\
Strain & 2 \\
Sprain & 1 \\
Abrasion & 3 \\
Ligament tear & 1 \\
Epistaxis & 1 \\
Total & 33 \\
\hline \multirow{2}{*}{ *Trauma types not listed in the table did not occur } \\
in this sample.
\end{tabular}

were treated with ice to the injured area). Although injury status before the tournament was not recorded, none of the injuries were reported as exacerbations of previous injuries. The rate of trauma was $1.3 \%$ overall (33/2498) with $0.8 \%$ (21/ 2498 ) requiring medical intervention (table 1). Only one participant was removed from the competition by the medical team. Using the NCAA definition of injury, this was the only injury among 2498 participants. This participant and two others were referred for follow up medical attention.

The cause in 20 of the 33 traumas $(61 \%)$ was participant contact. Ten $(30 \%)$ of the traumas were secondary to falls, one (3\%) being secondary to a twisting motion during competition (table 2).

Traumas were also categorised by diagnosis (table 3 ). Twenty five of the 33 traumas $(76 \%)$ were soft tissue contusions; 10 of these were subclinical by objective findings. None of the 25 soft tissue contusions required follow up medical treatment. Two of the traumas were strained muscles, and neither of these were referred for medical follow up. Two of the traumas were abrasions, neither of which required follow up. One episode of epistaxis was noted and was unrelated to trauma. The one injury was a grade 1 ligament injury of the knee.

The locations of the traumas were also noted (table 4). Almost half of the injuries were to the head and neck region (16/33). Most head and neck traumas were secondary to kicks to the face $(13 / 16)$. None required medical disqualification from the tournament.

Of the traumas of the extremities, most $(67 \%)$ occurred at the knee. Most knee traumas were soft tissue in nature and did not require either discontinuation from participation or follow up medical attention. Only three of the 11 extremity traumas were caused by blows delivered by the opponent. The others were secondary to falls, except for a twisting injury.

Four skeletal and spinal traumas were recorded. One competitor suffered a contusion to the ribs at T7-8. The patient continued with competition despite the trauma. The most serious of these traumas were those involving a sudden sharp whipping movement of the head or neck. Two of the four traumas were secondary to falls and resulted in soft tissue contusions. Neither of these traumas required disqualification from participation. 


\begin{tabular}{|c|c|}
\hline & Number \\
\hline \multicolumn{2}{|l|}{ Head and neck } \\
\hline \multicolumn{2}{|l|}{ Contusion } \\
\hline Head & 3 \\
\hline Face & 7 \\
\hline Neck & 3 \\
\hline Abrasion on face & 2 \\
\hline Epistaxis & 1 \\
\hline Total & 16 \\
\hline \multicolumn{2}{|l|}{ Upper extremity } \\
\hline Contusion & 2 \\
\hline Abrasion & 1 \\
\hline Total & 3 \\
\hline \multicolumn{2}{|l|}{ Lower extremity } \\
\hline Contusion & 6 \\
\hline Strain & 1 \\
\hline Ligament tear & 1 \\
\hline Total & 8 \\
\hline \multicolumn{2}{|l|}{ Groin } \\
\hline Contusion & 1 \\
\hline Total & 1 \\
\hline \multicolumn{2}{|l|}{ Trunk } \\
\hline \multicolumn{2}{|l|}{ Contusion } \\
\hline Rib & 1 \\
\hline Hip & 2 \\
\hline Strain & 1 \\
\hline Sprain & 1 \\
\hline Total & 5 \\
\hline All trauma & 33 \\
\hline
\end{tabular}

\section{DISCUSSION}

These findings contrast with those previously reported. Our results (0.4/1000 athlete exposures) show a much reduced injury rate from previous studies (25/1000 to $12.7 / 100$ athlete exposures). ${ }^{79-18}$ This reflects a significantly lower injury incidence in TKD tournaments in which protective measures were implemented for a wide range of participant skill levels. Furthermore, when the injury rate was tabulated by the NCAA classification system, the TKD tournaments had a lower injury rate than reported for many sports (table 5).

One can identify several possible explanations for the discrepancy between our findings and the results of previous TKD studies. Firstly, the tournaments in our study were sanctioned and overseen by a large national organisation. The participants were required to wear safety padding to protect the head, hands, elbows, feet, and groin. The organisers provided rules of engagement, which did not allow blows to the face and allowed only light contact to other target areas. These rules were impressed on the judges and were strictly enforced. Given that previous studies showed that most injuries occurred to the head and neck and injuries to this area were the most serious, it is not surprising that safety precautions aimed at reducing head and neck injury would result in a dramatic fall in the injury rate. Secondly, in many previous studies, the data were collected largely on those with the calibre to qualify for world championships. In contrast, the present subjects were derived from a heterogeneous group of participants from all walks of life, with ages ranging from 18 to 66. Therefore this study should better represent a typical "taekwondoist" in the United States. The data presented here, however, do include a large number of participants in a national tournament and therefore include many elite athletes. If the skill of the participant were largely responsible for the rate of
Table 5 Injury rates (per 1000 athlete exposures) for 13 sports in 1982/1983 to $1987 / 1988$ classified by the National Collegiate Athletic Association criteria ${ }^{20}$

\begin{tabular}{lll}
\hline Sport & Years sampled & Rate \\
\hline Wrestling & 5 & 10.03 \\
Women's soccer & 2 & 8.05 \\
Men's soccer & 2 & 7.78 \\
Women's gymnastics & 5 & 7.48 \\
Football & 6 & 6.57 \\
Men's lacrosse & 4 & 6.16 \\
Men's gymnastics & 2 & 5.80 \\
Ice hockey & 2 & 5.75 \\
Women's volleyball & 5 & 5.02 \\
Field hockey & 2 & 4.82 \\
Softball & 2 & 4.56 \\
Women's lacrosse & 5 & 3.77 \\
Baseball & 5 & 3.30 \\
Tae kwon do & & \\
\hline
\end{tabular}

Injury is defined as an ailment that keeps an athlete sidelined for at least one practice or contest. On exposure equals participation in one practice or contest.

injury, it would have been expected to have been higher than reported here. It is not entirely clear to what degree our findings of low injury incidence are due to the effect of implementation of safety measures or the nature of the participants. More studies are therefore indicated.

Finally, the organisers provided extensive medical coverage and doctors were given authority to disqualify participants on medical grounds. Therefore medical care was swift and appropriate. In fact, earlier studies had recommended both greater safety precautions and medical supervision to reduce the incidence of serious injuries. ${ }^{710^{14}}$ As only one participant was forced to cease competition because of injury, it can be asked whether provision of medical coverage had any effect on injury occurrence. It is possible that the presence of medical personnel led some combatants to be less or more aggressive towards their opponent. There may also have been an effect on the judges who met the medical personnel before the tournament and understood that the matches would be monitored closely. Conclusions on the effect of these variables are beyond the scope of this paper.

Our study may have underestimated the incidence of injury in TKD competition. Injury was only considered to have occurred if it resulted in interruption of competition. Therefore, under this definition, if a competitor sustained tissue damage and continued competing, this was not considered an injury. All tournament participants were not evaluated for injury; only those identified by the referee or the medical staff received medical evaluation. In addition, all follow up medical care was referred to the patient's family doctor and therefore follow up data were not available for our analysis.

However, it would be expected that the likelihood of injury would be higher than normal in tournaments of this magnitude. Several previous studies of world and national TKD competition support this assumption. ${ }^{1014}$ Notwithstanding, evidence from previous research indicates that training in martial arts such as TKD leads to a reduction in levels of hostility even in tense situations. ${ }^{21}$

The injury rate and severity of injuries in this study are significantly reduced compared with previous studies of TKD tournaments. In comparison with TKD competitions in which safety precautions were not in use, tournaments that emphasise limited contact, protective equipment, and medical supervision are safer. Also, the rate of injury is much lower than that reported in other common competitive sports. 


\section{Take home message}

The incidence of injury in TKD competition is reduced when protective measures are used. The data are impressive, as the rate of injury is far lower than in many of the non-contact sports encouraged in our educational systems. The data provide useful information for potential participants of TKD on the risks of injury.

\section{Authors' affiliations}

D T Burke, J C Schneider, H J Kim, G Levin, Department of Physical Medicine and Rehabilitation, Harvard Medical School, Boston, MA 02114, USA

K Barfoot, S Bryant, Louisana State University Medical Center, Section of Physical Medicine and Rehabilitation, 1542 Tulane Avenue, Box T6M-2, New Orleans, LA 70112, USA

\section{REFERENCES}

1 Ritter RH. Karate kids. Sports Care and Fitness 1989;2:14-19.

2 Birrer RB. Trauma epidemiology in the martial arts. The results of an eighteen-year international survey. Am J Sports Med 1996;24:S72-9.

3 Jaffe L, Minkoff J. Martial arts: a perspective on their evolution, injuries, and training formats. Orthop Rev 1988;17:208-9, 213-15, 220-1.

4 Johannsen HV, Noerregaard FO. Prevention of injury in karate. $\mathrm{Br} J$ Sports Med 1988;22:113-15

5 McLatchie GR, Davies JE, Culley JH. Injuries in karate: a case for medical control. J Trauma 1980;20:956-8.
6 McLatchie GR, Morris EW. Prevention of karate injuries: a progress report. Br J Sports Med 1977; 11:78-82.

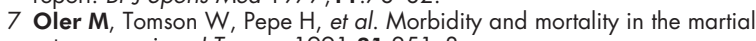
arts: a warning. J Trauma 1991;31:251-3.

8 Pieter W, Zemper ED. Injury rates in children participating in taekwondo competition. J Trauma 1997:43:89-95 (discussion 95-6).

9 Feehan $M$, Waller AE. Precompetition injury and subsequent tournament performance in full-contact taekwondo. Br J Sports Med 1995;29:258-62

10 Zemper ED, Pieter W. Injury rates during the 1988 US Olympic Team Trials for taekwondo. Br J Sports Med 1989:23:161-4.

11 Siana JE, Borum P, Kryger H. Injuries in taekwondo. Br J Sports Med 1986;20:165-6

12 Birrer R. Injuries in taekwondo. Br J Sports Med 1981;20:165-6.

13 Pieter W, Zemper ED, Head and neck injuries in young taekwondo athletes. J Sport Med Phys Fitness 1999:39:147-53.

14 Pieter W, Lufting R. Injuries at the 1991 taekwondo World Championships. J Sport Traumatol 1994; 16:49-57.

15 Pieter W, Bercades LT, Heijmans J. Competition injuries in Olympic taekwondo. Kinesiology 1998;30:22-30.

16 Pieter W, Zemper. Incidence of reported cerebral concussion in adult taekwondo athletes. J R Soc Health 1998;118:272-9.

17 Pieter W, Zemper ED. Competition injuries in adult taekwondo athletes. 5th IOC World Congress on Sports Sciences with the Annual Conference of Science and Medicine in Sport 1999.

18 Pieter W, Zemper ED. Head and neck injuries in young taekwondo athletes. J Sports Med Phys Fitness 1999;39:147-53.

19 United States Tae Kwon Do Alliance National Tournament 1993 and the United States Tae Kwon Do Alliance Tournament 1994. Tournament rules.

20 Dick R. National Collegiate Athletic Association Injury Surveillance System, 1982-1987. Mission, KS: NCAA; 1988.

21 Daniels K, Thornton E. Length of training, hostility and the martial arts: a comparison with other sporting groups. Br J Sports Med 1992;26:118-20. 